\title{
Interdisciplinary Problem-Based Learning in Gerontological Nursing
}

\author{
Rick Yiu Cho Kwan, Vico C. L. Chiang
}

School of Nursing, The Hong Kong Polytechnic University, Hung Hom, Kowloon, Hong Kong SAR

Gerontology is a study of processes associated with bodily changes from middle age through later life involving interdisciplinary investigations (Institute of Gerontology, 2021). Providing care for older people could be challenging because the presentation of disease symptoms are often atypical. Treatment effects often interact with their multimorbidity, leading to higher demand for support from an interdisciplinary team (Hofman, Van Den Hanenberg, Sierevelt \& Tulner, 2017; Tonelli et al., 2017). Overcoming barriers to interdisciplinary teams working together has been an issue in gerontology that challenges many healthcare professional training programme (Schapmire et al., 2018). The conventional education curriculum design of gerontological nursing mainly focuses on nursing; this may ignore the interdisciplinary teamwork aimed at resolving most care needs of older people in real settings. Problem-based learning (PBL) is considered a pedagogical approach that adequately scaffolds interdisciplinary learning in higher education, given that the issues of interdisciplinary learning are specifically addressed (Stentoft, 2017).

As an example regarding interdisciplinary learning and PBL, the School of Nursing in The Hong Kong Polytechnic University (PolyU) commenced an interdisciplinary subject for all first-year undergraduate students since the early 2010s. In PolyU, there are six disciplines providing training at the baccalaureate level for healthcare professionals. These include nursing, occupational therapy, physiotherapy, optometry, radiotherapy, and medical laboratory science. A subject on inter-disciplinary teamwork is a requirement for all students in the first year of healthcare professional undergraduate programmes. Students learn together from the faculty members and clinical specialists of different disciplines about their roles and collaborations in various healthcare settings (e.g., hospital and community).

In the undergraduate nursing programmes, all students have to enrol in a subject on gerontological nursing in their senior year (i.e., year 3 of a 5-year programme). We also adopt an interdisciplinary approach to frame this subject. We teach this subject from the perspective of nurses as being a player in the interdisciplinary team. In this subject, PBL is one of the teaching methods. A 7-step approach is as follow: 1) clarify terms and concepts, 2) define the problem, 3) analyze the issues, 4) draw a systematic inventory of the explanation, 5) formulate learning objectives, 6) collect additional information outside the group, and 7) synthesize newly acquired knowledge (Hemker, Prescher, \& Narciss, 2017). To start a series of scenarios about older people's ageing experiences at different stages and settings are provided to students in both written and video formats. Students form groups to identify and define the problems possibly faced by older people and their caregivers in the scenarios under the supervision of the group tutors' supervision. When the central issue is confirmed, the group members agree upon the learning objectives. Subsequently, with the tutor's guidance, students analyze problems by identifying the factors, giving explanations, posing solutions, and recalling personal experiences of the issues raised. Students have to report their learning progress following a pre-set schedule to their peers and the tutors. They learn through both face-to-face and online discussions with one another. At the end of the semester, students synthesize the

\section{Editorial}

pISSN 2288-8675 · elSSN 2508-9145

J Probl Based Learn 2021;8(1):1-3

https://doi.org/10.24313/jpbl.2021.00010

Received: February 22, 2021

Revised: March 12, 2021

Accepted: March 24, 2021

Corresponding author:

Rick Yiu Cho Kwan

GH506, School of Nursing, The Hong

Kong Polytechnic University, Hung

Hom, Kowloon, HKSAR

Tel: +852-2766-6546

Fax: +852-2364-9663

Email: rick.kwan@polyu.edu.hk
(C) Copyright 2021 International Society for Problem-Based Learning

(c) This is an Open Access article distributed under the terms of the Creative Commons Attribution Non-Commercial License (http://creativecommons.org/licenses/ by-nc/4.0/) which permits unrestricted non-commercial use, distribution, and reproduction in any medium, provided the original work is properly cited. 
acquired information through a presentation. In the presentation, students report the problems they identified from the scenario (i.e., those common clinical issues in real settings), the factors associated with the problems, the effects of various available interventions, and the implications to clinical practice. This assignment targets important learning objectives: PBL outcomes are established using pre-set rubrics that account for $50 \%$ of the subject assessment weighting.

Upon subject completion, students attend clinical practicum in settings where care for older people features an inter-disciplinary approach. Gerontological concepts are evident in postacute rehabilitation units for older people, geriatric day hospitals, and community nursing services. Students again use PBL methods to identify the clinical problems of older people in these real settings. The clinical instructors will discuss and guide students on approaches to the gerontology-specified problems (e.g., deconditioning) that can be managed by using an interdisciplinary approach (Ploutz-Snyder et al., 2018). Because students are novice learner, they are only expected to participate in the verbal discussion of some real cases with the clinical instructors on how nurses could contribute to solving the problems and improving the quality of care as a player of the interdisciplinary team. Students also have a chance to visit different departments (e.g., physical training centre), attend mini-lectures at clinical settings, and discuss with various healthcare professionals, to visualize how the problems are identified, diagnosed and solved by an interdisciplinary team.

To implement the interdisciplinary $\mathrm{PBL}$, the teaching team shares any consensus on some principles as outlined below (Stentoft, 2017):

- trigger students with complex and real-life problems;

- anchor the learning in a constructivist paradigm;

- ensure the learning is student-centred;

- encourage students to be self-directed and active;

- support students in critical thinking;

- ensure that teachers are the facilitators of the learning process;

- encourage students to work and learn in teams; and

- assist students in developing cognitive skills

In our experience, interdisciplinary PBL is very suitable for gerontological nursing education because the clinical problems in this area are highly complex, which always requires solutions from an interdisciplinary team perspective. For example, fall is a common problem in older people in hospitals (Masud \& Morris, 2001). However, the reasons are multiple, such as inappropriate use of psychotropic drugs, lower limb weakness, visual impairment, cognitive impairment, incontinence (Oliver, Daly, Martin,
\& McMurdo, 2004). To minimize the risk of falls, an effective interdisciplinary team is always needed to join hand to tackle these problems collaboratively. Successful interdisciplinary PBL depends on many factors beyond the curriculum structure design. In particular, the teaching team should involve faculty members from different disciplines (e.g. occupational therapy and physiotherapy); and be delivered in different settings (e.g., in university, hospital, and community) providing students with chances to develop their knowledge and skills through PBL. This approach students could transfer the knowledge acquired from the PBL to clinical practice. For the teaching team involved in PBL, self-observation and peer evaluations guided by validated instruments are very important (Garcia, James, Bischof, \& Baroffio, 2017). As such, the team could learn from one another effectively. The worthiness of the interdisciplinary PBL is equally important. Traditionally, the success of the learning and teaching approach is judged by the students' academic performance (e.g., examination). Student satisfaction is evaluated by the students' feedback questionnaires (Imanieh, Dehghani, Sobhani \& Haghighat, 2014). However, these measurements could be biased and fail to reflect the success of PBL strategies. Notably, PBL may also effectively promote independent learning, self-directed learning, self-reflectivity, critical thinking, and group process skills (Cooke \& Moyle, 2002). There are various tools available to measure student abilities on critical thinking (Carter, Creedy \& Sidebotham, 2015), self-directed learning (Cheng, Kuo, Lin \& Lee-Hsieh, 2010), and teamwork (Gordon et al., 2016). Evidence shows that problem-based learning improves nursing students' ability beyond academic performance, such as critical thinking and self-directed learning (Choi, Lindquist \& Song, 2014;Oja, 2011). Academics should consider adding evidence of these outcomes to the traditional outcome markers such as academic performance.

\section{REFERENCES}

Carter, A. G., Creedy, D. K., \& Sidebotham, M. (2015). Evaluation of tools used to measure critical thinking development in nursing and midwifery undergraduate students: a systematic review. Nurse Education Today, 35(7), 864-874.

Cheng, SF., Kuo, CL., Lin, KC., \& Lee-Hsieh, J. (2010). Development and preliminary testing of a self-rating instrument to measure self-directed learning ability of nursing students. International Journal of Nursing Studies, 47(9), 1152-1158.

Choi, E., Lindquist, R., \& Song, Y. (2014). Effects of problem-based learning vs. traditional lecture on Korean nursing students' critical thinking, problem-solving, and self-directed learn- 
ing. Nurse Education Today, 34(1), 52-56.

Cooke, M., \& Moyle, K. (2002). Students' evaluation of problem-based learning. Nurse Education Today, 22(4), 330-339.

Garcia, I., James, R. W., Bischof, P., \& Baroffio, A. (2017). Self-observation and peer feedback as a faculty development approach for problem-based learning tutors: A program evaluation. Teaching and Learning in Medicine, 29(3), 313-325.

Gordon, CJ., Jorm, C., Shulruf, B., Weller, J., Currie, J., Lim, R., \& Osomanski, A. (2016). Development of a self-assessment teamwork tool for use by medical and nursing students. BMC Medical Education, 16(1), 1-7.

Hemker, L., Prescher, C., \& Narciss, S. (2017). Design and evaluation of a problem-based learning environment for teacher training. Interdisciplinary Journal of Problem-Based Learning, 11(2), 10.

Hofman, M., Van Den Hanenberg, F., Sierevelt, I., \& Tulner, C. (2017). Elderly patients with an atypical presentation of illness in the emergency department. The Netherlands Journal of Medicine, 75(6), 241-246.28741583

Imanieh, MH., Dehghani, SM., Sobhani, AR., \& Haghighat, M. (2014). Evaluation of problem-based learning in medical students' education. Journal of Advances in Medical Education Professionalism, 2(1), 1.25512911

Institute of Gerontology. (2021). Definition of Gerontology. Retrieved from https://iog.publichealth.uga.edu/what-is-gerontol- ogy/.

Masud, T., \& Morris, RO. (2001). Epidemiology of falls. Age and Ageing, 30(suppl 4), 3-7.

Oja, KJ. (2011). Using problem-based learning in the clinical setting to improve nursing students' critical thinking: an evidence review. Journal of Nursing Education, 50(3), 145-151.

Oliver, D., Daly, F., Martin, FC., \& McMurdo, ME. (2004). Risk factors and risk assessment tools for falls in hospital in-patients: a systematic review. Age and Ageing, 33(2), 122-130.

Ploutz-Snyder, LL., Downs, M., Goetchius, E., Crowell, B., English, KL., \& Ploutz-Snyder, R., et al. (2018). Exercise training mitigates multisystem deconditioning during bed rest. Medicine and Science in Sports and Exercise, 50(9), 1920.

Schapmire, TJ., Head, BA., Nash, WA., Yankeelov, PA., Furman, CD., \& Wright, RB., et al. (2018). Overcoming barriers to interprofessional education in gerontology: the interprofessional curriculum for the care of older adults. Advances in medical education and practice, 9, 109-118.

Stentoft, D. (2017). From saying to doing interdisciplinary learning: Is problem-based learning the answer? Active Learning in Higher Educatione, 18(1), 51-61.

Tonelli, M., Wiebe, N., Straus, S., Fortin, M., Guthrie, B., \& James, M. T., et al. (2017). Multimorbidity, dementia and health care in older people:a population-based cohort study. CMAJ open, 5(3), E623-E631. 